Article

\title{
Effects of a Short Heat Treatment Period on the Pullout Resistance of Shape Memory Alloy Fibers in Mortar
}

\author{
Min Kyoung Kim ${ }^{1} \mathbb{D}$, Dong Joo Kim ${ }^{1, *}$, Young-Soo Chung ${ }^{2}$ and Eunsoo Choi ${ }^{3, *}$ \\ 1 Department of Civil and Environmental Engineering, Sejong University, 2019, Neungdong-ro, Gwangjin-Gu, \\ Seoul 05006, Korea \\ 2 Department of Civil Engineering, Chung-Ang University, 221 Heuksuk-dong, Dongjak-gu, \\ Seoul 156-756, Korea \\ 3 Department of Civil Engineering, Hongik University, 72-1 Sangsu-dong, Mapo, Seoul 121-791, Korea \\ * Correspondence: djkim75@sejong.ac.kr (D.J.K.); eunsoochoi@hongik.ac.kr (E.C.); \\ Tel.: +82-2-3408-3820 (D.J.K.); +82-2-320-3060 (E.C.); Fax: +82-2-3408-4332 (D.J.K.); +82-2-322-1244 (E.C.)
}

Received: 15 June 2019; Accepted: 14 July 2019; Published: 16 July 2019

\begin{abstract}
The feasibility of the crack closure of cementitious composites reinforced with shape memory alloy (SMA) fibers was investigated by performing single-fiber pullout tests. To demonstrate the fast crack closing ability, in this study, a heat treatment $\left(300^{\circ} \mathrm{C}\right)$ was applied for a short time (10 min). A short heat treatment was applied for $10 \mathrm{~min}$, after the slip reached $0.5 \mathrm{~mm}$, to activate the shape memory effects of cold-drawn SMA fibers. Two types of alloys were investigated, NiTi and $\mathrm{NiTiNb}$, with two geometries, either smooth or dog-bone-shaped. During the heat treatment, the pullout stress of the SMA fibers initially decreased due to thermal extension, and then increased after heating for 1-3 min, resulting from the shape memory effects. However, their pullout stress recovery during and after the heat treatment was different for the different alloys and fiber geometries. The NiTi fibers generally produced a higher and faster recovery in terms of their pullout stress than the $\mathrm{NiTiNb}$ fibers, while the dog-bone-shaped fibers showed a faster pullout stress recovery than the smooth fibers.
\end{abstract}

Keywords: fibers; smart materials; fiber/matrix bond; physical properties; heat treatment

\section{Introduction}

Considerable research has been performed on extending the service life of civil infrastructures through the prevention of early concrete deterioration. As an early deterioration countermeasure, various high-performance construction materials, such as ultra-high-performance concretes (UHPCs), high-performance fiber-reinforced cementitious composites (HPFRCCs), and self-healing concretes (SHCs), have been developed by numerous researchers [1-6]. However, even the high-performance construction materials are unable to close existing concrete cracks in a short time for a quick (or instantaneous) repair of concrete infrastructure. Although both the UHPCs and HPFRCCs have been shown to produce a significantly high tensile strength and cracking control capacity by generating multiple microcracks during tensile strain hardening [1,7], as well as a larger redistribution capacity of stresses [8], they remain unable to close existing cracks. Although the SHCs can heal (or fill) cracks by precipitating crystalline calcium carbonates within the cracks, they require a water supply and a minimum of a few days to heal the cracks [5,9]. Therefore, the aforementioned high-performance construction materials cannot be applied for urgent repairs, even though they have shown a superior prevention of early concrete deterioration. 
Due to the issues noted above, the authors of this study propose the development of short shape memory alloy (SMA) fiber-reinforced cement composites with a fast crack closing capacity. Kim et al. $[10,11]$ have already demonstrated that an $8 \mathrm{~h}$ long-term heat treatment of cold-drawn SMA fibers significantly enhanced the pullout resistance of fibers embedded in a mortar matrix due to the diameter recovery in the cold-drawn SMA fibers. However, it is quite difficult to maintain a heat treatment for a long time on site. Kim et al. [12] demonstrated the pre-stressing effect of shape memory alloy fiber-reinforced cementitious composites (SMA-FRCCs) under direct tension after a short (10 $\mathrm{min}$ ) heat treatment. They reported that the shape memory effect can be activated by short-term heat treatment for $10 \mathrm{~min}$. Consequently, in this study, we investigated whether a short (10 min) heat treatment period could activate the shape memory effect and eventually close existing cracks.

This research is aimed at developing SMA-FRCCs with a crack closing capacity, as well as pre-stressing effects by utilizing the shape memory effect. The detailed objectives are (1) to investigate the geometry change in the SMA fibers during short heating periods, (2) to investigate the heat treatment effects on the pullout resistance of the SMA fibers, and (3) to discover the influence of different SMA fiber geometries and compositions on the pullout resistance recovery during and after the short heat treatment period.

\section{Shape Memory Alloy Fiber-Reinforced Cementitious Composites (SMA-FRCCs)}

Considerable research has been performed on the application of SMA wires or bars to civil infrastructures and buildings by activating their shape memory effects and utilizing their super-elastic characteristics. Researchers have reported on the effectiveness of wrapping SMA wires around concrete cylinders or columns to enhance ductility and strength by utilizing the confinement effects induced from shape memory effects. Choi et al. [13] proposed a new jacketing method to confine concrete cylinders and/or reinforced concrete columns using SMA wires, demonstrating that the shape memory effect of SMA wires was considerably more effective than the steel jacketing method for generating confinement effects [14,15]. Tran et al. [16] also reported that the shape memory-induced confinement effect of SMA wires significantly increased the strength and ductility of concrete cylinder samples. Furthermore, SMA wires have also been used to reinforce cement-based matrices in order to generate pre-stressing effects in the cement composites; Sawaguchi et al. [17] applied Fe-Mn-Si-based shape memory alloys containing $\mathrm{NbC}$ to generate pre-stressing effects.

In addition to the confinement and pre-stressing effects obtained through SMA wire application, the self-crack closing behavior of composites reinforced with SMA wire has also been investigated. SMA wires added to epoxy or cement mortar were applied to generate a crack closing capability in a beam [18-20]. In order to create the crack closing ability, it is important to have a strong interfacial bond strength between the fiber or wire and the surrounding matrix. Accordingly, Umezaki [18] investigated the pullout resistance of SMA wires, reporting that spiral SMA wires produced a higher pullout resistance than smooth SMA wires. Wang et al. [21] investigated the internal stress distribution to prevent debonding at the SMA fiber and epoxy matrix interface, in order to eventually utilize the shape memory effect more efficiently. Watanabe et al. [22] also reported that the interfacial bond strength of Fe-based SMA wire was notably enhanced as the amount of pre-strain in the SMA wires increased. Kuang and $\mathrm{Ou}$ [23] developed a self-healing concrete beam by utilizing the super-elastic behavior of SMAs and the cohering characteristic of the repairing adhesive.

Although several researchers have studied the behavior of SMA wire-reinforced composites in an attempt to utilize their shape memory effect, the majority of their SMA applications have been limited to continuous SMA wires rather than short SMA fibers. The implementation of short SMA fibers has rarely been attempted, and the behavior of short SMA fiber-reinforced cementitious composites is yet to be discovered. In this study, to develop short SMA fiber-reinforced cementitious composites with a self-crack closing ability, the pullout resistance of these fibers embedded in a mortar matrix was systematically investigated by applying a short heat treatment period. 


\section{Experiments}

An experimental program was designed to investigate the feasibility of crack closure of SMA-FRCCs by applying a short heat treatment period $(10 \mathrm{~min})$. The pullout stress recovery of SMA fibers embedded in a mortar matrix was investigated during this heat treatment with single-fiber pullout tests. Two types of SMAs (NiTi and $\mathrm{NiTiNb}$ ) were used, while two types of fiber geometries (smooth and dog-bone-shaped) were investigated experimentally. First, the geometric changes in the diameter and length of cold-drawn SMA fibers during the short heat treatment time were investigated by analyzing stereoscopic microscope images taken every minute of the heat treatment. Second, the pullout stress versus slip (and time) responses of the SMA fibers in a mortar matrix were investigated by performing single-fiber pullout tests. The conditions of the single-fiber pullout tests are provided in Table 1. During the pullout tests, a short heat treatment period was applied while maintaining a constant slip $(0.5 \mathrm{~mm})$ for $10 \mathrm{~min}$ once the fiber slip reached $0.5 \mathrm{~mm}$. Then, the fiber was pulled further until complete fiber pullout was achieved.

Table 1. Conditions of the single-fiber pullout tests.

\begin{tabular}{|c|c|c|c|c|}
\hline Alloy & Fiber Diameter $(\mathrm{mm})^{a}$ & Shape & Heat Treatment & Notation \\
\hline \multirow{4}{*}{$\mathrm{NiTi}$} & \multirow{4}{*}{$1.0 \rightarrow 0.96$} & \multirow[b]{2}{*}{ Smooth } & No & NT_S_N \\
\hline & & & Yes & NT_S_H \\
\hline & & \multirow{2}{*}{ Dog-bone shaped } & No & NT_D_N \\
\hline & & & Yes & NT_D_H \\
\hline \multirow{4}{*}{$\mathrm{NiTiNb}$} & \multirow{4}{*}{$1.12 \rightarrow 1.08$} & \multirow{2}{*}{ Smooth } & No & NTN_S_N \\
\hline & & & Yes & NTN_S_H \\
\hline & & \multirow{2}{*}{ Dog-bone shaped } & No & NTN_D_N \\
\hline & & & Yes & NTN_D_H \\
\hline
\end{tabular}

$\mathrm{a} \rightarrow$ refers to the diameter change after the cold-drawing process.

\subsection{Materials and Sample Preparation}

The composition and strength of the mortar matrix are provided in Table 2; the compressive strength of the mortar was $55 \mathrm{MPa}$. The properties of the SMA fibers investigated in this study are summarized in Table 3. Four types of SMA fibers (NT_S, NT_D, NTN_S, and NTN_D, described in Table 1) were used and are shown in Figure 1. The NiTi (NT) alloy contained 50\% nickel by atomic composition, whereas the NiTiNb (NTN) alloy contained $41 \%$ nickel, $50 \%$ titanium, and $9 \%$ niobium. The initial $1.0 \mathrm{~mm}$ diameter of the NT wires was reduced to $0.96 \mathrm{~mm}$ after the cold drawing process.

Table 2. Matrix mixture composition by weight ratio and compressive strength.

\begin{tabular}{|c|c|c|c|c|c|}
\hline Cement (Type 3) & Fly Ash & Silica Sand & $\begin{array}{l}\text { High-Range Water-Reducing } \\
\text { Admixture }\end{array}$ & Water & $\mathbf{f}^{\prime}{ }_{\mathrm{ck}}(\mathrm{MPa})$ \\
\hline 1.00 & 0.15 & 1.00 & 0.009 & 0.35 & 55 \\
\hline
\end{tabular}

Table 3. Properties of the shape memory alloy (SMA) fibers.

\begin{tabular}{|c|c|c|c|c|c|c|c|c|}
\hline \multirow{2}{*}{ Notation } & \multirow{2}{*}{$\begin{array}{c}\text { Length } \\
\text { (mm) }\end{array}$} & \multirow{2}{*}{$\begin{array}{l}\text { Diameter } \\
(\mathrm{mm})\end{array}$} & \multirow{2}{*}{$\begin{array}{c}\text { Young's } \\
\text { Modulus (GPa) }\end{array}$} & \multirow{2}{*}{$\begin{array}{c}\text { Tensile } \\
\text { Strength (MPa) }\end{array}$} & \multicolumn{4}{|c|}{ Transformation Temperature $\left({ }^{\circ} \mathrm{C}\right)$} \\
\hline & & & & & $\mathbf{M}_{\mathrm{f}}$ & $\mathbf{M}_{\mathrm{s}}$ & $\mathbf{A}_{\mathrm{s}}$ & $\mathbf{A}_{\mathrm{f}}$ \\
\hline NT_S & \multirow{2}{*}{30} & \multirow{2}{*}{0.96} & \multirow{2}{*}{41} & \multirow{2}{*}{973} & \multirow{2}{*}{0.7} & \multirow{2}{*}{36.7} & \multirow{2}{*}{43.2} & \multirow{2}{*}{62.8} \\
\hline NT_D & & & & & & & & \\
\hline $\begin{array}{l}\text { NTN_S } \\
\text { NTN_D }\end{array}$ & 30 & 1.08 & 21 & 1270 & - & $-100 \geq$ & $-100 \leq$ & - \\
\hline
\end{tabular}

${ }^{a} \mathrm{M}_{\mathrm{f}}$ is the temperature at the end of martensitic transformation, $\mathrm{M}_{\mathrm{s}}$ is the temperature at the start of martensitic transformation, $\mathrm{A}_{\mathrm{s}}$ is the temperature at the start of austenitic transformation, and $\mathrm{A}_{\mathrm{f}}$ is the temperature at the end of austenitic transformation. 


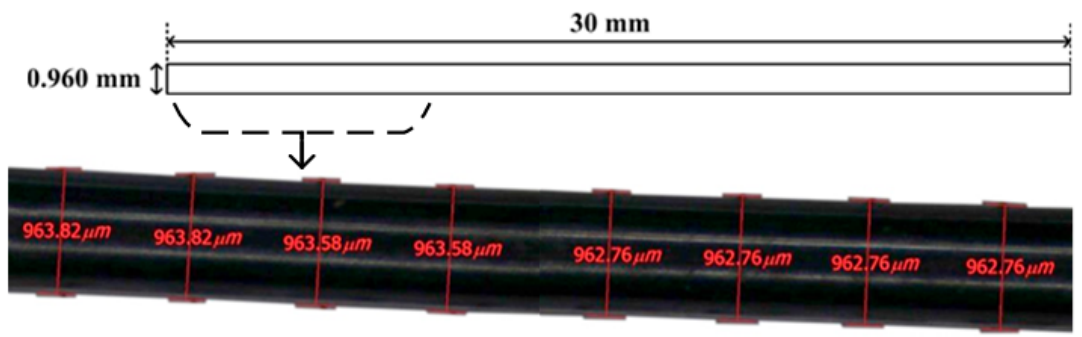

(a)

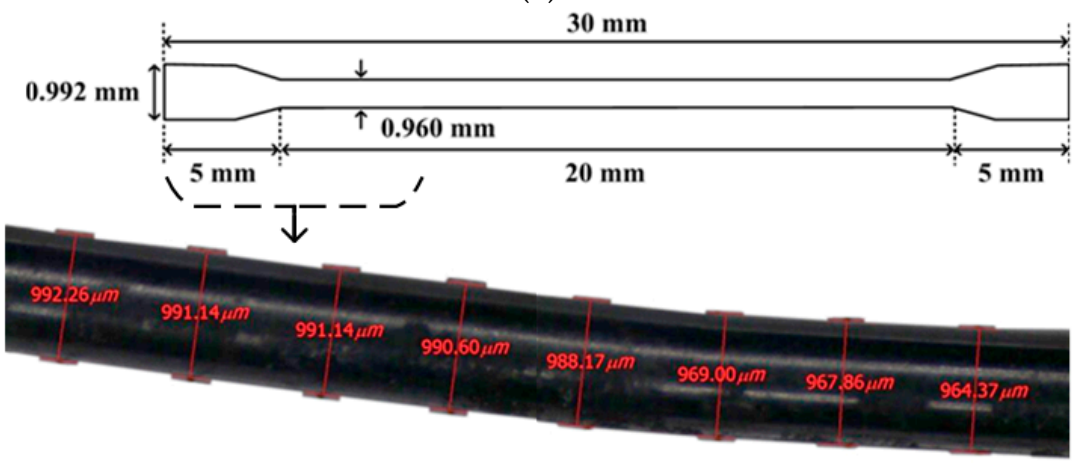

(b)

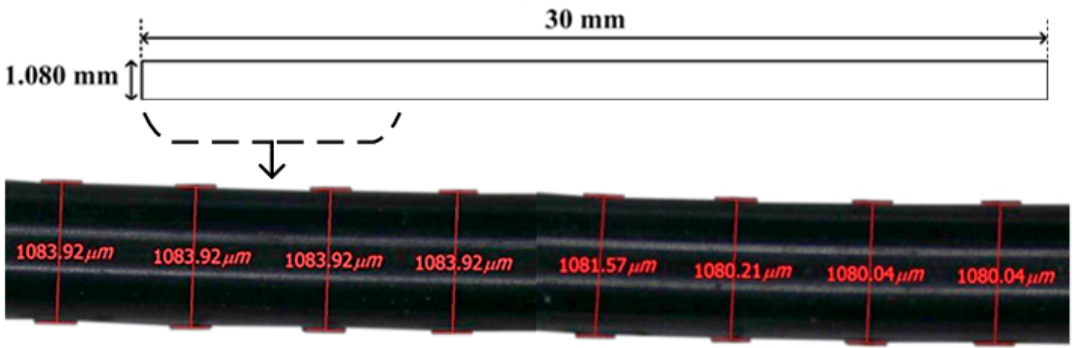

(c)

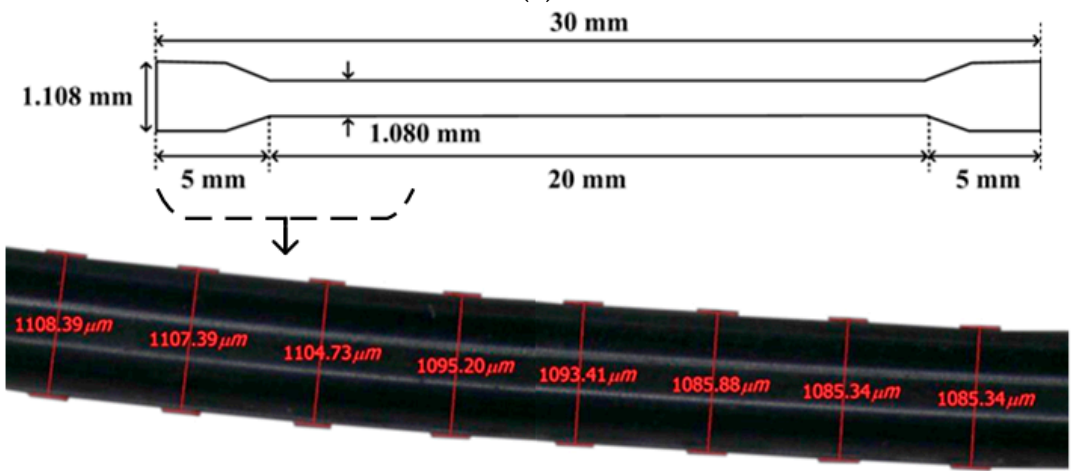

(d)

Figure 1. Shape memory alloy (SMA) fiber geometries, for (a) NiTi smooth (NT_S), (b) NiTi dog-bone-shaped (NT_D), (c) NiTiNb smooth (NTN_S), and (d) NiTiNb dog-bone-shaped (NTN_D).

In comparison, the NTN wires with a $1.12 \mathrm{~mm}$ initial diameter were also cold-drawn to a $1.08 \mathrm{~mm}$ reduced diameter. The transformation temperatures of both cold-drawn NT and NTN fibers are summarized in Table 3.

Six samples of each type of SMA fiber were prepared, with three samples pulled out with the heat treatment, whereas the others were tested with no heat treatment. The notation NT_S_N in Table 1 represents the pullout samples of the NT smooth (S) fiber with no $(\mathrm{N})$ heat treatment, while samples of the NTN dog-bone-shaped (D) fiber with the short heat $(\mathrm{H})$ treatment periods were designated as 
NTN_D_H. The fibers were first installed in fiber holding devices to maintain the embedment length $(15 \mathrm{~mm})$ and inclination angle $\left(90^{\circ}\right)$ of the fiber within a mortar matrix. The devices holding the SMA fibers were then placed in molds to produce bell-shaped pullout samples. The mortar matrix was prepared using a Hobart-type laboratory mixer with a $20 \mathrm{~L}$ capacity. A detailed procedure on mixing and curing this type of sample can be found in Kim et al. [10,11]. The pullout samples, after curing in water for 14 days, were dried and tested after 16 days at room temperature in the laboratory.

\subsection{Test Setup and Procedure}

The length and diameter of the SMA fibers could be measured by analyzing images taken by a stereoscopic microscope with a Huvitz Lusis HC-30MU camera (Huvitz, Gyeonggi-do Province, Korea). A short period of heat treatment was applied using a heat gun (DeWalt D26411) (DeWalt, Towson, MD, USA). The operation temperature of the heat gun was set at $300^{\circ} \mathrm{C}$ and the airflow speed was $250 \mathrm{~L} / \mathrm{min}$. The heating gun was installed at a $35 \mathrm{~mm}$ distance from the SMA fibers during the heat treatment. The heat treatment in the experiment was performed using a commercial heating gun for the practical application, even in structural members. The temperature applied by using a heat gun was about $300^{\circ} \mathrm{C}$, so that it would not generate any significant damage on the cement-based matrix [24]. Therefore, it was applied to raise the temperature of SMA fibers (over $\mathrm{A}_{\mathrm{f}}$ ) embedded within the mortar matrix. Moreover, heat treatment at $300{ }^{\circ} \mathrm{C}$ for $10 \mathrm{~min}$ does not significantly affect the tensile strength of SMA-FRCCs (reduced about 10\%) [12], unlike SFRCs, which exhibit about a $40 \%$ reduction in tensile strength by heating at $300^{\circ} \mathrm{C}$ for $2 \mathrm{~h}$ prior to testing [25]. During the pullout resistance investigation of the SMA fibers, a universal test machine with a $500 \mathrm{kgf}$ capacity was used and the displacement speed was maintained at $1 \mathrm{~mm} / \mathrm{min}$ during the fiber pullout. To avoid any slip of fiber in the grip system, the other part of embedded fiber was fully held with a sufficient pressure in the grip, as can be seen in Figure 2. The test procedure is as follows: the fiber was initially pulled out to a $0.5 \mathrm{~mm}$ slip with a velocity of $1 \mathrm{~mm} / \mathrm{min}$; then, the $0.5 \mathrm{~mm}$ slip was kept constant for $10 \mathrm{~min}$; and finally, the fiber was further pulled with the same $1 \mathrm{~mm} / \mathrm{min}$ velocity until complete pullout was achieved. The test set-up for the single-fiber pullout test is shown in Figure 2.

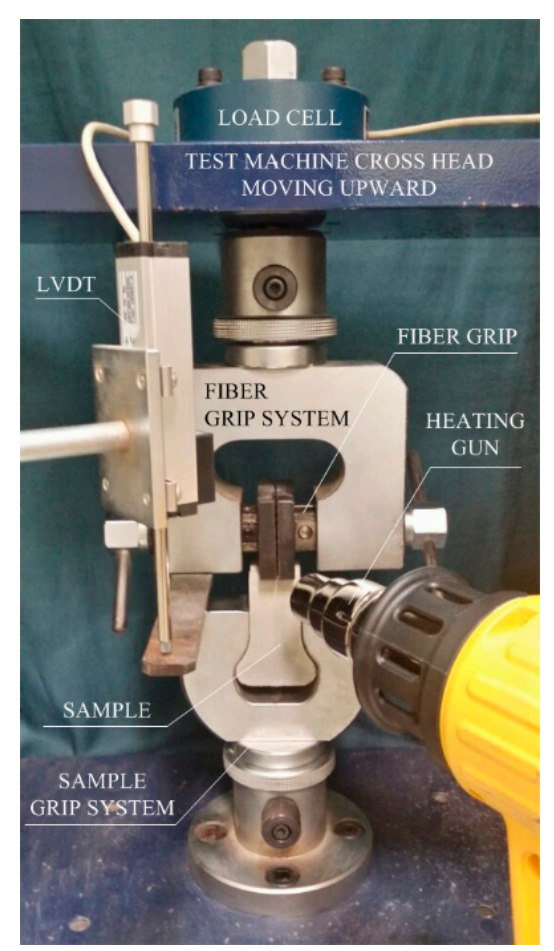

Figure 2. Test setup for the single-fiber pullout test. 


\section{Results and Discussion}

\subsection{Length and Diameter of Cold-Drawn SMA Fibers during the Short Heat Treatment Period}

The changes in the diameter and length of the cold-drawn SMA fibers during the short heat treatment time are provided in Figure 3; Figure 3a-d shows the changes in the length and diameter of the NT_S, NT_D, NTN_S, and NTN_D samples, respectively. During the 10 min heat treatment, the lengths of the cold-drawn SMA fibers clearly decreased, whereas their diameters, which were originally reduced by the cold-drawing process, increased due to the shape memory effect.

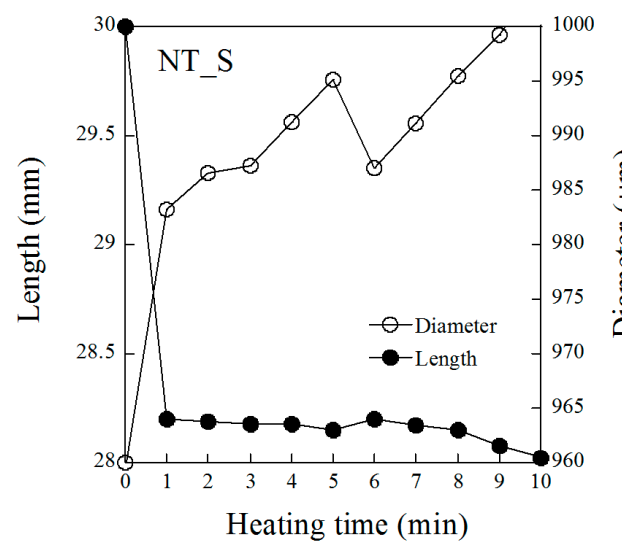

(a)

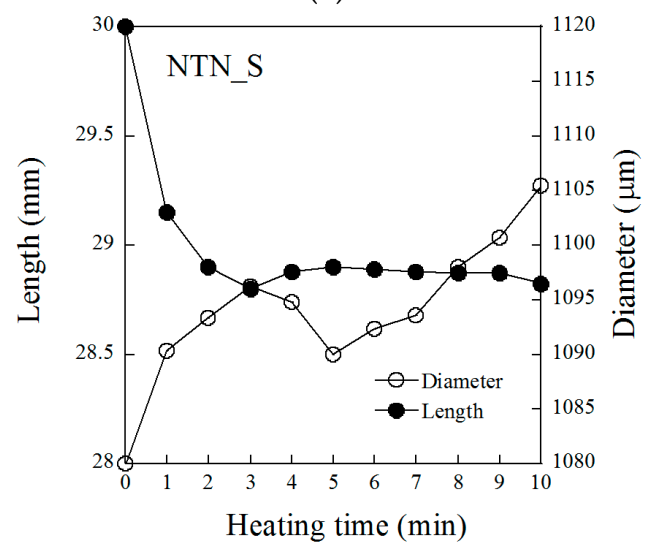

(c)

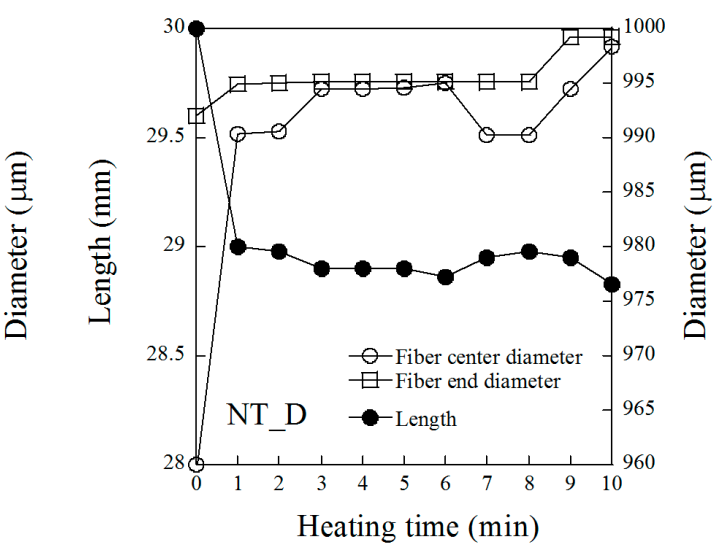

(b)

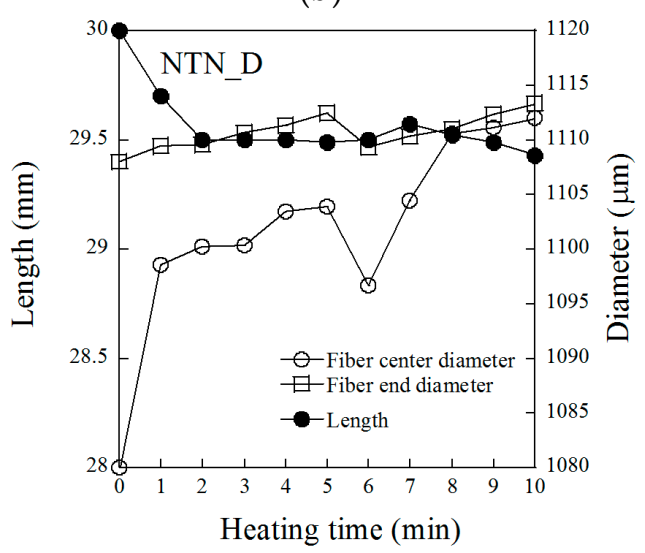

(d)

Figure 3. Effects of heating time on the length and diameter of the cold-drawn shape memory alloy (SMA) fibers for (a) NT_S, (b) NT_D, (c) NTN_S, and (d) NTN_D.

Although all SMA fibers had noticeable changes in their diameter and length, the changes were different, based on the type of alloy and geometry. During the heat treatment, the NT_S length was shortened from 30 to $28 \mathrm{~mm}(-6.67 \%)$, while that of the NTN_S decreased from 30 to $28.8 \mathrm{~mm}(-4.0 \%)$, as shown in Figure 3a,c, respectively. On the other hand, the NT_S diameter expanded from 960 to $1000 \mu \mathrm{m}(+4.17 \%)$, while the NTN_S increased from 1080 to $1105 \mu \mathrm{m}(+2.31 \%)$. In addition, the NT_D also presented a greater length reduction (from 30 to $28.8 \mathrm{~mm}$ ) and wider expansion of the diameter (from 960 to $998 \mu \mathrm{m}$ ) than the NTN_D, as shown in Figure 3b,d. Therefore, the NT series generally showed higher shape memory effects, for both the diameter expansion and length reduction, than the NTN series. Moreover, the S geometry of the SMA fibers produced greater changes in both length and diameter than the D-shaped geometry, as shown in Figure 3. For example, the length of the NT_D decreased from 30 to $28.8 \mathrm{~mm}$, whereas the NT_S changed from 30 to $28 \mathrm{~mm}$. In addition, the length and diameter of all SMA fibers changed significantly within 1 to 3 min of heat treatment. Based on this observation, a short-term heat treatment of only a few minutes could successfully activate the 
shape memory effect of cold-drawn SMA fibers. Therefore, in this study, the heat treatment period was determined to be 10 min during the pullout test.

\subsection{Pullout Stress Versus Slip Response}

The pullout stress versus slip curves of the NT fibers are provided in Figure 4, while those of the NTN fibers are shown in Figure 5. The pullout responses of the SMA fibers clearly changed relative to the different fiber alloys and geometries, and if the heat treatment was applied. The dog-bone-shaped SMA fibers largely produced a better pullout resistance than the smooth SMA fibers because the former utilized a mechanical interaction between the bulged end of the fiber and mortar matrix, unlike the smooth fibers, which only used the frictional bond resistance at the interface. In addition, for the short heat treatment samples, after the $0.5 \mathrm{~mm}$ initial fiber pullout, there was a noticeable increase in the pullout stress, even though the slip was a constant $0.5 \mathrm{~mm}$, as shown in Figure $4 \mathrm{~b}, \mathrm{~d}$ and Figure $5 \mathrm{~b}, \mathrm{~d}$. These figures additionally provide close-up graphs of the pullout response from the 0 to $1.0 \mathrm{~mm}$ slip. During the initial pullout to the $0.5 \mathrm{~mm}$ slip, the pullout stress reached its first peak point at a slip between 0.1 and $0.3 \mathrm{~mm}$, and then decreased until the slip was $0.5 \mathrm{~mm}$. When the slip reached $0.5 \mathrm{~mm}$, it was kept constant for $10 \mathrm{~min}$. For the test series with the heat treatment, the pullout stress at $0.5 \mathrm{~mm}$ slip immediately increased during the heat treatment above the initial peak stress. However, for the samples without a heat treatment, there was no change in the pullout stress at the $0.5 \mathrm{~mm}$ slip. Furthermore, among the dog-bone-shaped fibers, the NTN consistently showed a higher pullout resistance than the NT fibers, regardless of heat treatment. The higher pullout resistance of the NTN_D fibers over the NT_D fibers likely originated from the higher strength of the NTN.

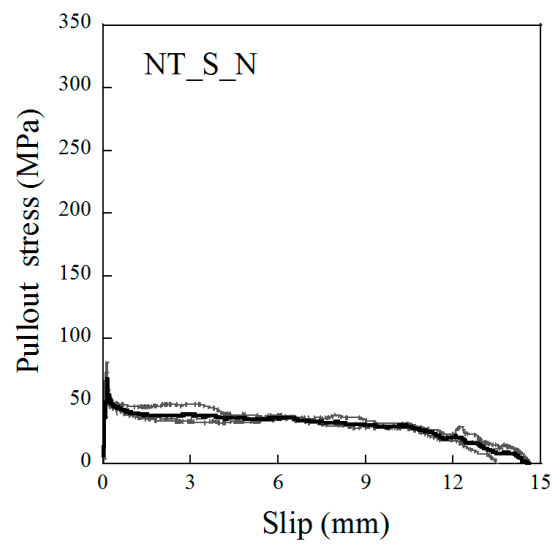

(a)

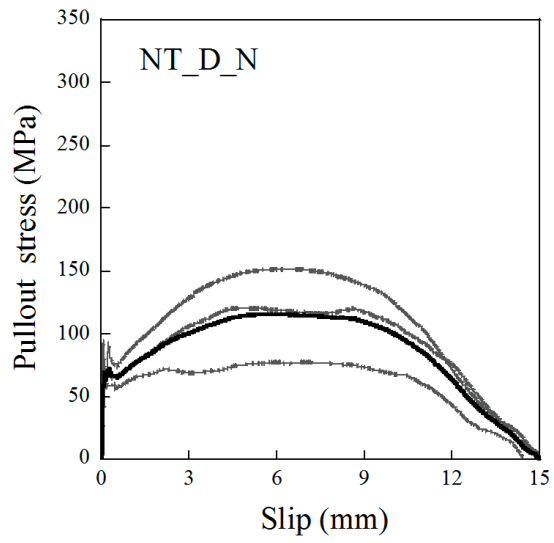

(c)

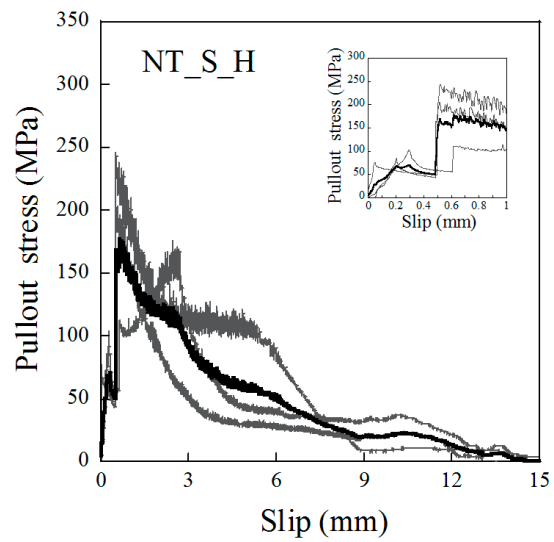

(b)

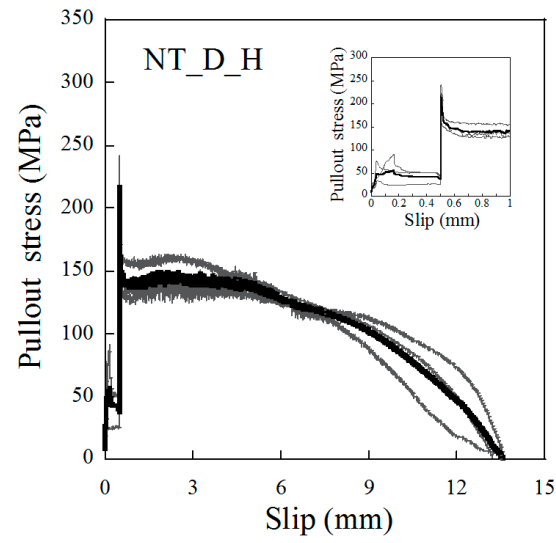

(d)

Figure 4. Pullout stress versus slip response of the NiTi fibers for (a) NT_S_N, (b) NT_S_H, (c) NT_D_N, and (d) NT_D_H. The insets in (b) and (d) are close-ups of the 0 to $1 \mathrm{~mm}$ slip regions for each graph. 


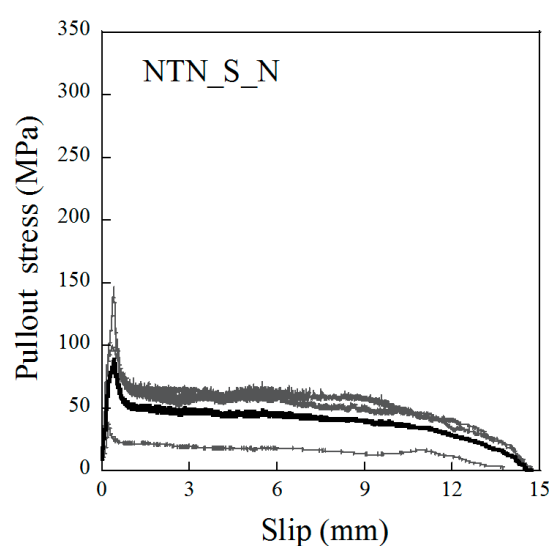

(a)

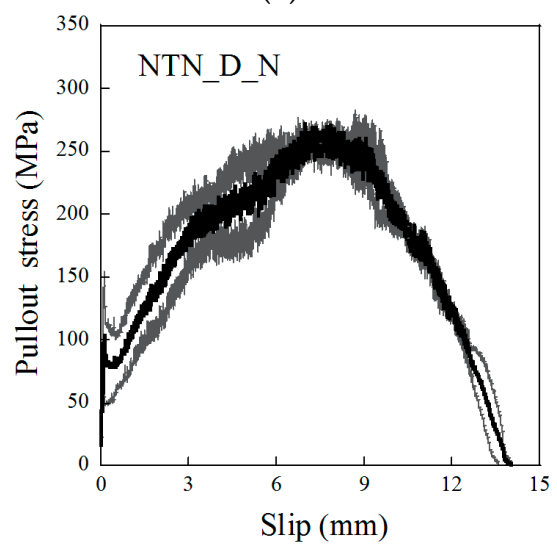

(c)

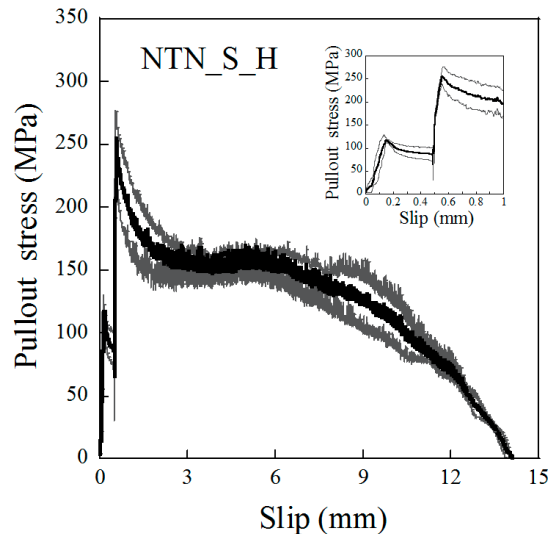

(b)

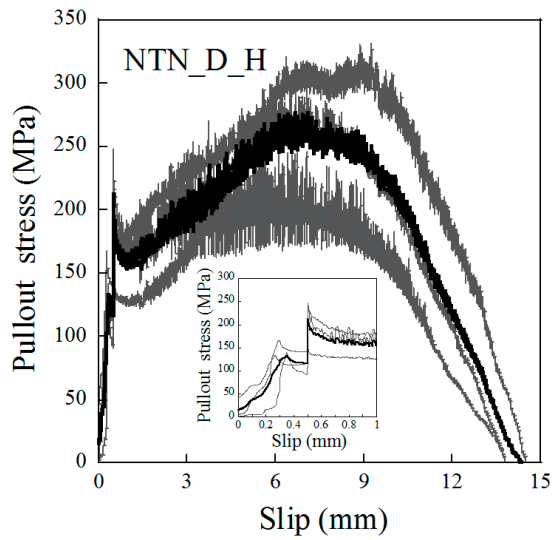

(d)

Figure 5. Pullout stress versus slip response of the NiTiNb fibers for (a) NTN_S_N, (b) NTN_S_H, (c) NTN_D_N, and (d) NTN_D_H. The insets in (b) and (d) are close-ups of the 0 to $1 \mathrm{~mm}$ slip regions for each graph.

Kim et al. [10] investigated the effects of heat treatment on the pullout resistance of SMA fibers embedded in the mortar matrix. They applied the pre-heat treatment (at $200{ }^{\circ} \mathrm{C}$ for $8 \mathrm{~h}$ ) prior to the pullout test and then additional heat treatment $\left(200^{\circ} \mathrm{C}\right)$ was applied during the pullout test. The heat treatment of SMA fibers considerably recovered their reduced diameter after cold-drawing and consequently increased their pullout resistance. Moreover, Kim et al. [11] applied the pre-heat treatment $\left(80^{\circ} \mathrm{C}\right.$ for $\left.7 \mathrm{~h}\right)$ prior to the pullout test and then additional heat treatment $\left(100^{\circ} \mathrm{C}\right)$ during the pullout test. They reported that the heat treatment generally increased the pullout resistance regardless of the fiber compositions. Comprehensively, the enhanced pullout resistance of SMA fibers after heat treatment demonstrates their crack closing potentials in fiber-reinforced cementitious composites. However, current research requires not only a long time for pre-heat treatment of at least $7 \mathrm{~h}$, but also continuous heat treatment during the pullout test. Therefore, it is necessary to reduce the time for heat treatment. Consequently, the pullout resistance was found to be enhanced by applying the heat treatment $\left(300^{\circ} \mathrm{C}\right)$ for only a short time $(10 \mathrm{~min})$ during the pullout test without pre-heat treatment.

\subsection{Pullout Resistance during the Short Heat Treatment Period}

The changes in the SMA fiber pullout stress during the short heat treatment period are provided in Figures 6 and 7 for the NT and NTN fibers, respectively. For the NT fibers, as shown in Figure 6a,c, if there was no heat treatment, the pullout stress was a constant value as the slip amount was kept at $0.5 \mathrm{~mm}$ for $10 \mathrm{~min}$. However, for the series with the heat treatment, the pullout stress decreased at the beginning of the heat treatment, and then started to increase significantly, after 1-3 min, to a value greater than the residual pullout stress $\left(\mathrm{P}_{0.5, \mathrm{re}}\right)$ after $5 \mathrm{~min}$ of heating. After $10 \mathrm{~min}$ of heating, 
the pullout stress reached the recovered pullout stress $\left(\mathrm{P}_{0.5, \mathrm{rc}}\right)$, as illustrated in Figure 8 , and the $\mathrm{P}_{0.5, \mathrm{rc}}$ of the NT fibers was higher than the $\mathrm{P}_{0.5, \text { re }}$, regardless of the fiber geometry. When the fiber pullout was restarted after the $10 \mathrm{~min}$ heat treatment, the pullout stress of the fiber instantly increased to the re-pullout stress $\left(\mathrm{P}_{0.5, \mathrm{rp}}\right)$, as shown in Figure $6 \mathrm{~b}, \mathrm{~d}$ and Figure 8 . The $\mathrm{P}_{0.5, \mathrm{rp}}$ was significantly higher than the $\mathrm{P}_{0.5, \mathrm{rc}}$. The pullout resistance of the NT fibers initially decreased at the beginning of the heat treatment, owing to the thermal extension (or elongation) of the fibers. Then, the NT fibers began recovering the pullout resistance after 1-3 $\mathrm{min}$, by activating their shape memory effects, i.e., shortening the length and expanding the diameter of the fibers; these eventually produced a higher $\mathrm{P}_{0.5, \mathrm{rc}}$ than the $\mathrm{P}_{0.5, \text { re. }}$ In Figure 8, the NTN fibers showed a similar response to the heat treatment as the NT fibers, with both maintaining a constant value for $10 \mathrm{~min}$ after the $0.5 \mathrm{~mm}$ initial slip when there was no heat treatment, whereas their values varied noticeably during the short heat treatment period. However, the $\mathrm{P}_{0.5, \mathrm{rc}}$ of the NTN fibers was lower than their $\mathrm{P}_{0.5, \mathrm{re}}$, unlike the NT fibers.

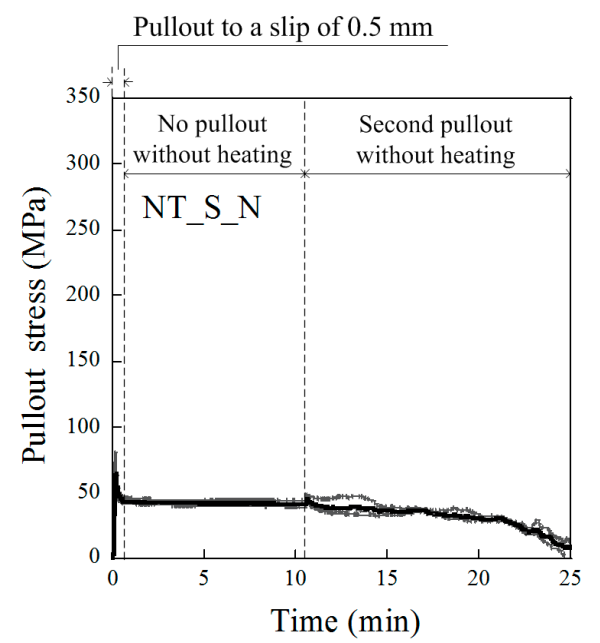

(a)

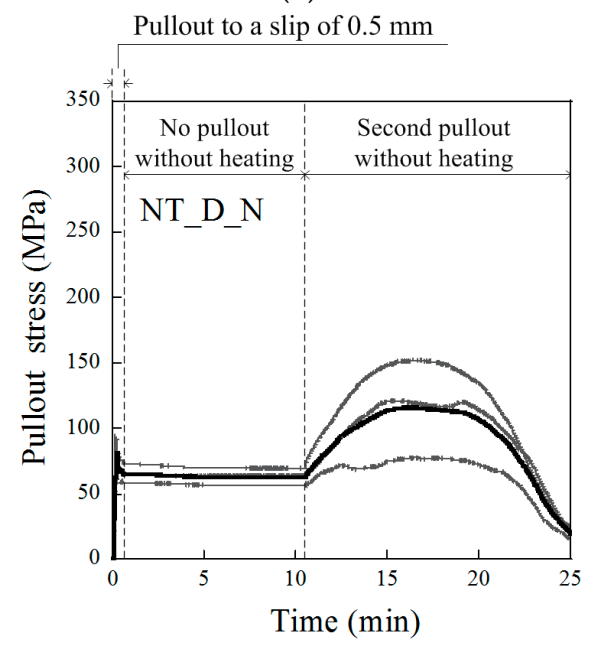

(c)

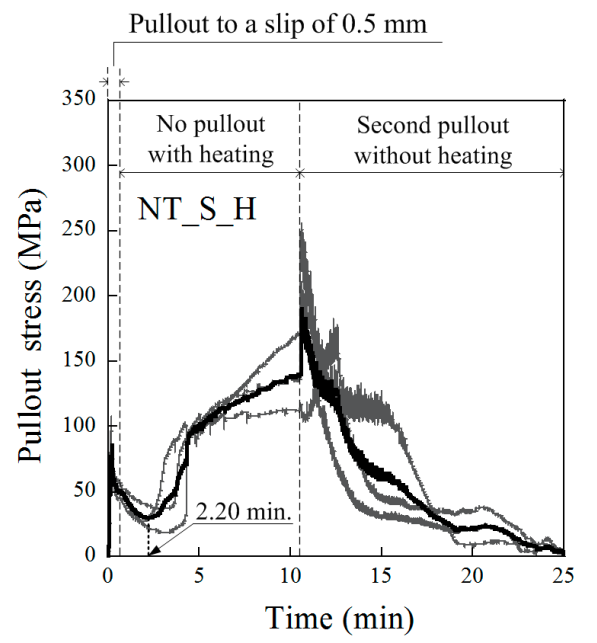

(b)

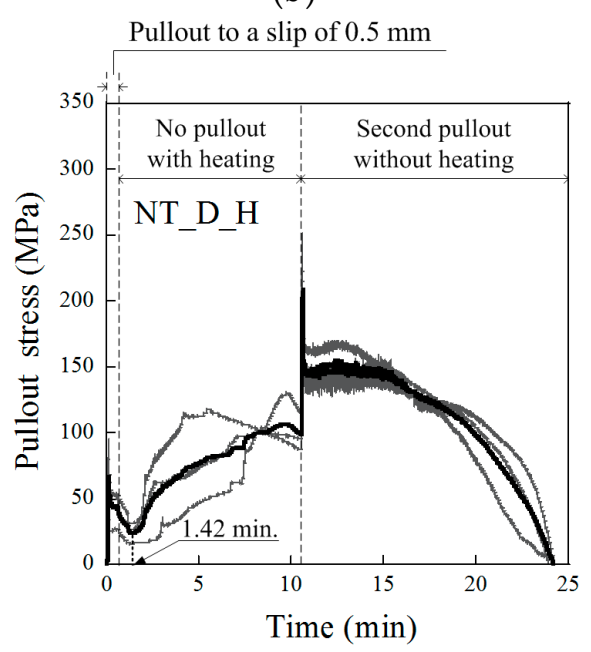

(d)

Figure 6. History of the pullout stress versus time for the NiTi fibers of (a) NT_S_N, (b) NT_S_H, (c) NT_D_N, and (d) NT_D_H. 


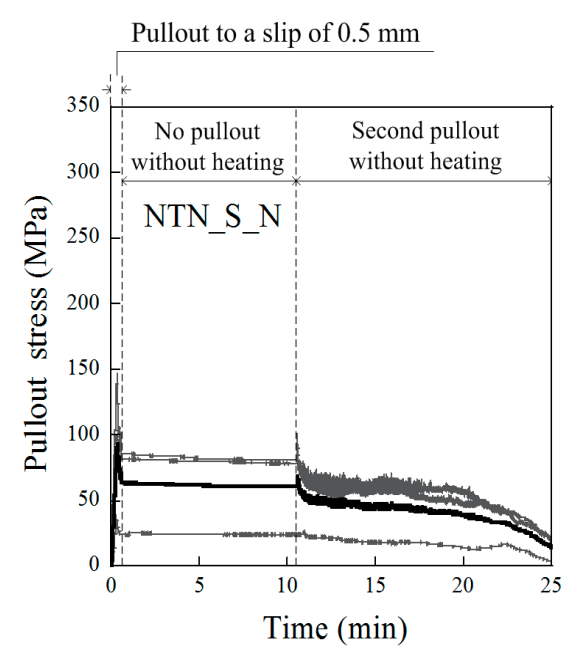

(a)

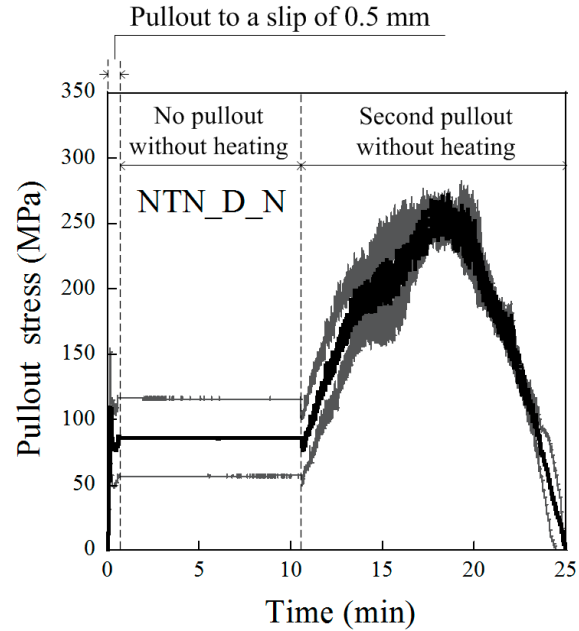

(c)

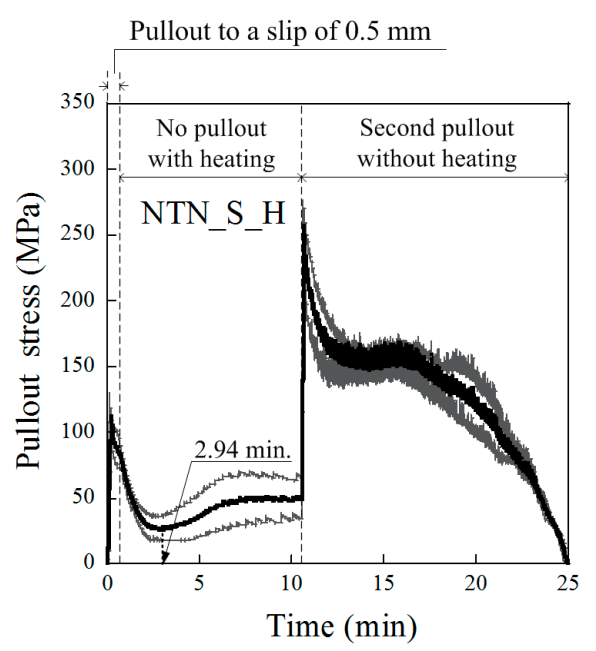

(b)

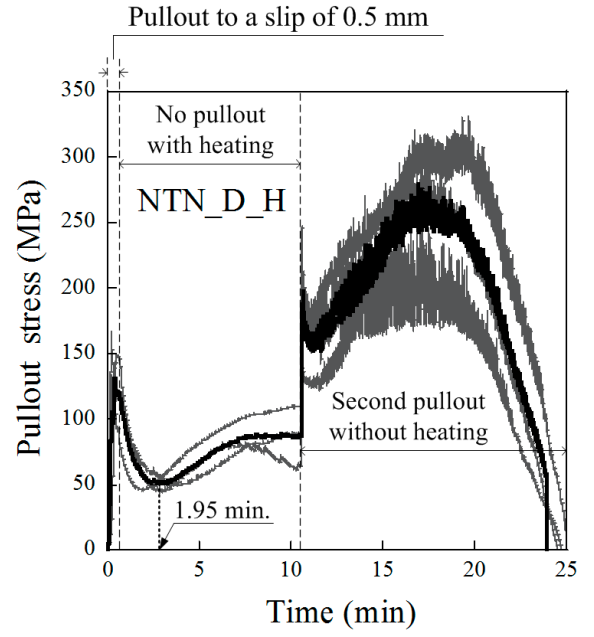

(d)

Figure 7. History of the pullout stress versus time for the NiTiNb fibers of (a) NTN_S_N, (b) NTN_S_H, (c) NTN_D_N, and (d) NTN_D_H.

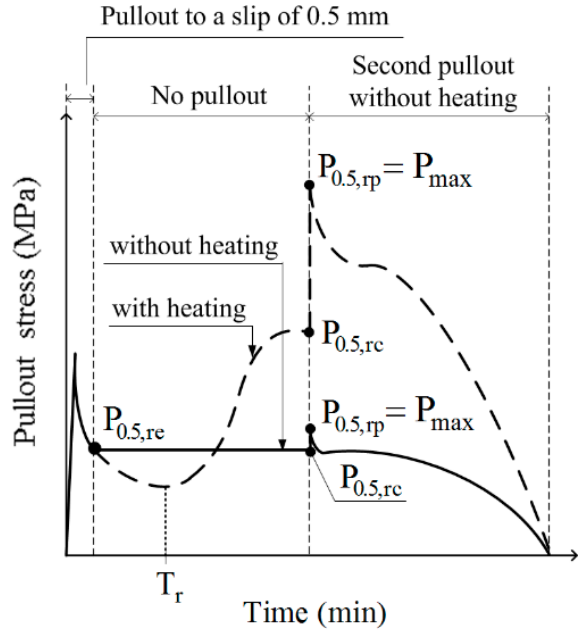

(a)

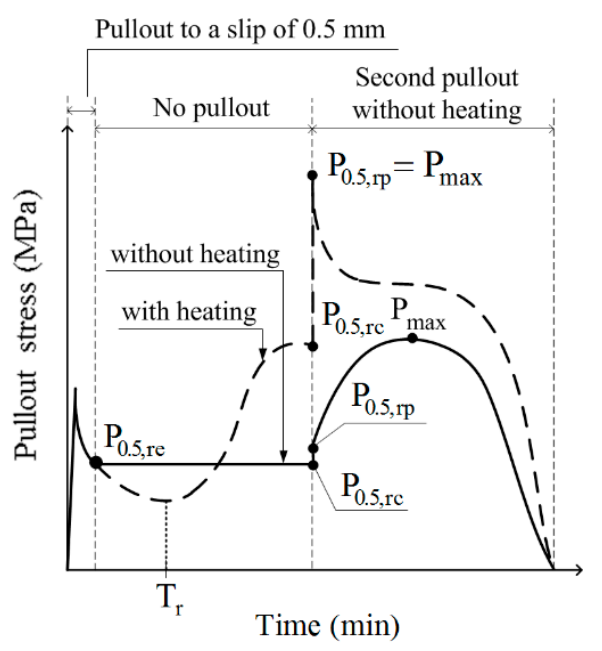

(b)

Figure 8. Cont. 


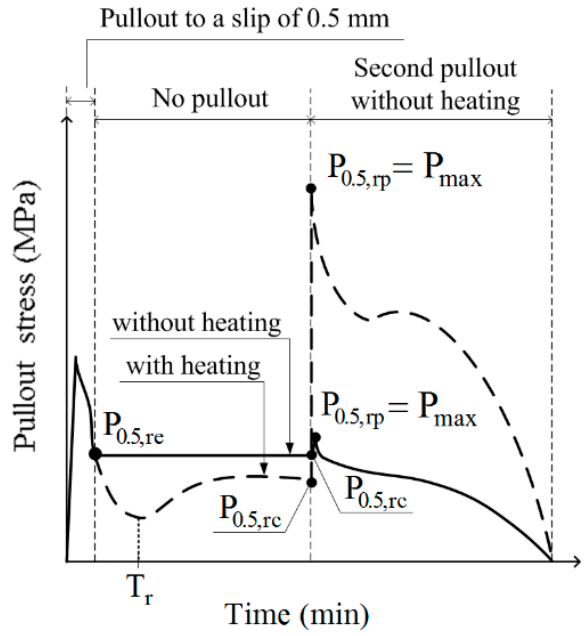

(c)

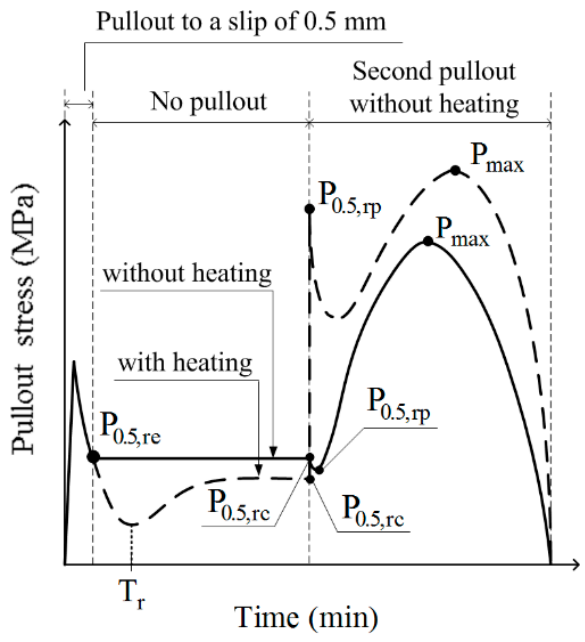

(d)

Figure 8. Typical pullout stress versus time curves of the shape memory alloy (SMA) fibers, showing the pullout parameters and pullout stress recovery for (a) NT_S, (b) NT_D, (c) NTN_S, and (d) NTN_D for samples with heating (solid lines) or without heating (dashed lines).

To quantitatively compare the pullout resistances of all test series, several parameters describing the SMA fiber pullout behavior are summarized in Table 4, including the $\mathrm{P}_{0.5, \mathrm{re}}, \mathrm{P}_{0.5, \mathrm{rc}}, \mathrm{P}_{0.5, \mathrm{rp}}$, maximum pullout stress $\left(\mathrm{P}_{0.5, \max }\right)$, and pullout energy after the $0.5 \mathrm{~mm}$ slip to complete pullout (PE). After the short heat treatment time, the PE values were noticeably enhanced, as presented in Table 4, although the degree of enhancement varied according to the geometry and alloy of the fibers. The PE values of the dog-bone-shaped SMA fibers were clearly higher than those of the smooth SMA fibers: the value of NT_D_H was 1063.2 MPa-m, whereas that of NT_S_H was 525.5 MPa-m.

Table 4. Pullout test results.

\begin{tabular}{|c|c|c|c|c|c|c|}
\hline Notation & Sample & $P_{0.5, \text { re }}(\mathrm{MPa})$ & $\mathrm{P}_{0.5, \mathrm{rc}}(\mathrm{MPa})$ & $P_{0.5, \text { rp }}(\mathrm{MPa})$ & $P_{\max }(\mathrm{MPa})$ & PE (MPa-mm) \\
\hline \multirow{5}{*}{ NT_S_N } & SP1 & 41.5 & 39.5 & 43.6 & 43.6 & 272.2 \\
\hline & SP2 & 46.2 & 44.2 & 48.8 & 48.8 & 335.2 \\
\hline & SP3 & 43.2 & 42.1 & 46.1 & 46.1 & 317.1 \\
\hline & Aver. $^{a}$ & 43.7 & 41.9 & 45.7 & 45.7 & 308.2 \\
\hline & $\mathrm{STD}^{\mathrm{b}}$ & 1.9 & 1.9 & 2.1 & 2.1 & 26.5 \\
\hline \multirow{5}{*}{ NT_S_H } & SP1 & 56.6 & 112.5 & 181.9 & 181.9 & 471.3 \\
\hline & SP2 & 44.5 & 171.2 & 214.5 & 214.5 & 382.9 \\
\hline & SP3 & 49.9 & 136.1 & 254.9 & 254.9 & 658.0 \\
\hline & Aver. & 50.3 & 139.9 & 190.6 & 190.6 & 525.5 \\
\hline & STD & 4.9 & 24.1 & 29.9 & 29.9 & 114.7 \\
\hline \multirow{5}{*}{ NT_D_N } & SP1 & 58.7 & 56.0 & 58.1 & 94.4 & 578.7 \\
\hline & SP2 & 73.5 & 69.1 & 47.9 & 152.3 & 1137.0 \\
\hline & SP3 & 64.2 & 64.2 & 65.8 & 121.2 & 959.1 \\
\hline & Aver. & 65.6 & 63.1 & 65.7 & 116.4 & 904.0 \\
\hline & STD & 6.4 & 5.4 & 7.3 & 23.7 & 232.9 \\
\hline \multirow{5}{*}{ NT_D_H } & SP1 & 51.2 & 95.0 & 251.0 & 251.0 & 1123.9 \\
\hline & SP2 & 53.2 & 87.6 & 232.3 & 232.3 & 959.7 \\
\hline & SP3 & 26.3 & 115.2 & 193.7 & 193.7 & 1106.7 \\
\hline & Aver. & 43.6 & 99.3 & 208.8 & 208.8 & 1063.2 \\
\hline & STD & 12.2 & 11.7 & 23.9 & 23.9 & 73.7 \\
\hline
\end{tabular}


Table 4. Cont.

\begin{tabular}{|c|c|c|c|c|c|c|}
\hline Notation & Sample & $\mathbf{P}_{0.5, \text { re }}(\mathrm{MPa})$ & $\mathbf{P}_{0.5, \mathrm{rc}}(\mathrm{MPa})$ & $\mathbf{P}_{0.5, \mathrm{rp}}(\mathrm{MPa})$ & $P_{\max }(\mathrm{MPa})$ & PE (MPa-mm) \\
\hline \multirow{5}{*}{ NTN_S_N } & SP1 & 23.9 & 23.9 & 26.3 & 26.3 & 181.5 \\
\hline & SP2 & 85.9 & 81.0 & 85.5 & 85.5 & 641.8 \\
\hline & SP3 & 81.6 & 78.3 & 99.8 & 99.8 & 652.3 \\
\hline & Aver. & 63.8 & 61.1 & 69.3 & 69.3 & 494.3 \\
\hline & STD & 28.3 & 26.3 & 31.8 & 31.8 & 219.5 \\
\hline \multirow{4}{*}{ NTN_S_H } & SP1 & 73.1 & 33.7 & 239.4 & 239.4 & 1472.1 \\
\hline & SP2 & 95.9 & 66.4 & 276.6 & 276.6 & 1780.3 \\
\hline & Aver. & 84.5 & 50.0 & 257.5 & 257.5 & 1625.9 \\
\hline & STD & 11.4 & 16.4 & 18.6 & 18.6 & 154.1 \\
\hline \multirow{4}{*}{ NTN_D_N } & SP1 & 57.2 & 57.1 & 57.4 & 273.8 & 2073.3 \\
\hline & SP2 & 115.8 & 115.8 & 116.3 & 282.2 & 2358.4 \\
\hline & Aver. & 84.8 & 84.5 & 86.7 & 271.8 & 2375.9 \\
\hline & STD & 29.3 & 29.4 & 29.5 & 4.2 & 142.6 \\
\hline \multirow{5}{*}{ NTN_D_H } & SP1 & 148.0 & 63.8 & 247.0 & 296.1 & 2600.0 \\
\hline & SP2 & 92.8 & 109.9 & 154.7 & 330.4 & 2865.0 \\
\hline & SP3 & 120.9 & 115.1 & 236.2 & 269.0 & 2031.1 \\
\hline & Aver. & 120.3 & 96.6 & 198.3 & 280.1 & 2850.8 \\
\hline & STD & 22.5 & 23.1 & 41.2 & 25.1 & 347.9 \\
\hline
\end{tabular}

${ }^{a}$ Aver.: average values; ${ }^{b}$ STD: standard deviation.

\subsection{Pullout Stress Recovery Starting Time $\left(T_{r}\right)$ during the Heat Treatment}

As observed in the pullout stress versus time curves of the SMA fibers during the short-term heat treatment in both Figures 6 and 7, their pullout stress first decreased at the beginning of the heat treatment and then began increasing to the end of the heat treatment. The pullout stress recovery starting time was quite different based on the type of SMA fiber geometry and alloy. Table 5 provides the recovery starting times $\left(\mathrm{T}_{\mathrm{r}}\right)$ of the pullout stress relative to the test series during the short heat treatment period. The average $T_{\mathrm{r}}$ values of the test series (NT_S_H, NT_D_H, NTN_S_H, and NTN_D_H) were $2.20,1.42,2.94$, and $1.95 \mathrm{~min}$, respectively. The NT fibers usually produced faster $\mathrm{T}_{\mathrm{r}}$ than the NTN fibers, while the D-shaped fibers produced faster $T_{r}$ than the $S$ fibers. The earlier pullout stress recovery of the dog-bone-shaped SMA fibers is thought to originate from their higher PE values, indicating a superior pullout resistance. Accordingly, the SMA fibers with a deformed geometry generating a larger $\mathrm{PE}$ are favorable for generating a faster crack closing ability. However, the parameters influencing the recovery start time $\left(\mathrm{T}_{\mathrm{r}}\right)$ require further investigation.

Table 5. Pullout stress recovery starting time during heating $\left(\mathrm{T}_{\mathrm{r}}\right)$.

\begin{tabular}{ccc}
\hline Notation & Sample & $\mathbf{T}_{\mathbf{r}}$ (min.) \\
\hline \multirow{3}{*}{ NT_S_H } & SP1 & 3.35 \\
& SP2 & 1.93 \\
& SP3 & 3.17 \\
& Average & $\mathbf{2 . 2 0}$ \\
\hline \multirow{3}{*}{ NT_D_H } & SP1 & 1.47 \\
& SP2 & 1.51 \\
& SP3 & 1.42 \\
NTN_S_H & Average & $\mathbf{1 . 4 2}$ \\
& SP1 & 4.20 \\
& SP2 & 2.77 \\
& Average & $\mathbf{2 . 9 4}$ \\
\hline \multirow{2}{*}{ NTN_D_H } & SP1 & 3.14 \\
& SP2 & 1.93 \\
& SP3 & 1.95 \\
& Average & $\mathbf{1 . 9 5}$ \\
\hline
\end{tabular}




\subsection{Pullout Stress Recovery Ratios}

The ratios $R_{1}$ and $R_{2}$, between the pullout stresses, $P_{0.5, r e}, P_{0.5, r c}$, and $P_{0.5, r p}$, were calculated to quantify the crack closing ability of the SMA fibers during and after the short-term heat treatment. The ratio between the $P_{0.5, r c}$ and $P_{0.5, \text { re }}$ is denoted as $R_{1}$, which represents the potential crack closing ability. The ratio between the $P_{0.5, r p}$ and $P_{0.5, \text { re }}$ was additionally analyzed and denoted as $R_{2}$, which is thought to correlate with the ability to prevent crack reopening. Both $R_{1}$ and $R_{2}$ ratios are provided in Figure $9 b$. The NT fibers generally produce higher recovery ratios than the NTN fibers, as shown in Figure 9b; the values of $\mathrm{R}_{1}$ were $2.78,2.28,0.59$, and 0.80 for NT_S_H, NT_D_H, NTN_S_H, and NTN_D_H, respectively, while those of $\mathrm{R}_{2}$ were $3.79,4.79,3.05$, and 1.65 for NT_S_H, NT_D_H, NTN_S_H, and NTN_D_H, respectively. The $\mathrm{R}_{1}$ ratios of the NT fibers were higher than 1.0, whereas those of the NTN fibers were less than 1.0. Therefore, the pullout stress recovery during the short heat treatment period is higher for the NT fibers than the NTN fibers. Additionally, $\mathrm{R}_{1}$ values below 1.0 are not sufficient for closing cracks, whereas those higher than 1.0 are indicative of a satisfactory or strong crack closing capacity. The $\mathrm{R}_{2}$ ratios of the NT fibers were also higher than the NTN fibers. Therefore, the NT fibers after the heat treatment displayed a higher pullout resistance during the second pullout process.

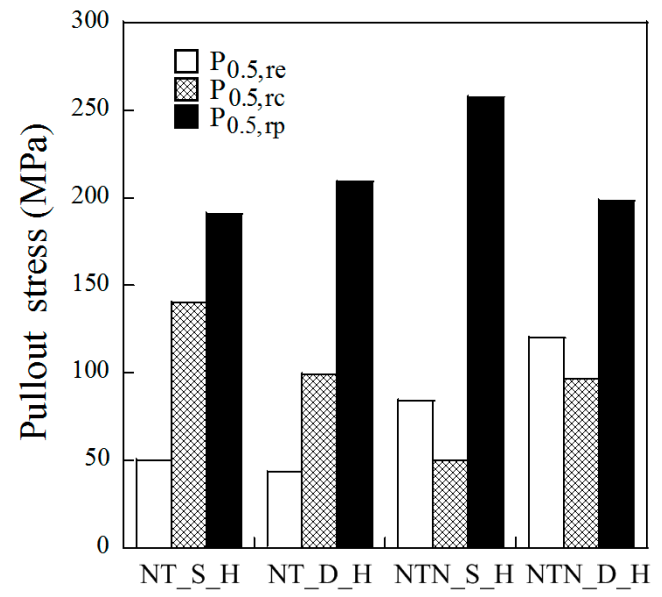

(a)

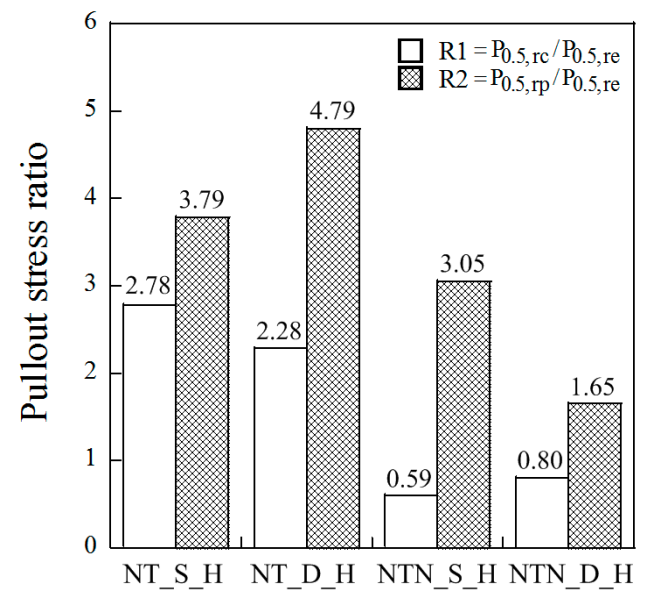

(b)

Figure 9. (a) Pullout stress and (b) pullout stress ratios owing to the heat treatment, for the different samples.

\subsection{Pullout Energy Ratios}

The short heat treatment period also noticeably increased the amount of pullout energy after the $0.5 \mathrm{~mm}$ initial slip to complete fiber pullout, as provided in Table 4 and Figure 10a.

The enhanced SMA fiber pullout energy after the heat treatment originated from the lateral recovery of the fiber diameter due to shape memory effects. To quantitatively compare the heat treatment effect on the PE, the pullout energy ratios between samples with and without heat treatment were estimated and are shown in Figure 10. The pullout energy ratios of the NT_S, NT_D, NTN_S, and NTN_D were $1.71,1.18,3.29$, and 1.20, respectively. The higher pullout energy ratio is thought to be favorable for resisting crack reopening. The NTN_S fiber produced the highest pullout energy ratio, while the NTN_D fiber produced the highest pullout energy. In addition, it was also evident that the smooth fibers generated higher pullout energy ratios than the dog-bone-shaped fibers because the pullout energy of the $\mathrm{D}$ fiber was much higher than that of the $\mathrm{S}$ fiber for the series without heat treatment. The PE value of NTN_S_N was $494.3 \mathrm{MPa}-\mathrm{mm}$, while that of NTN_D_N was $2375 \mathrm{MPa}-\mathrm{mm}$. 


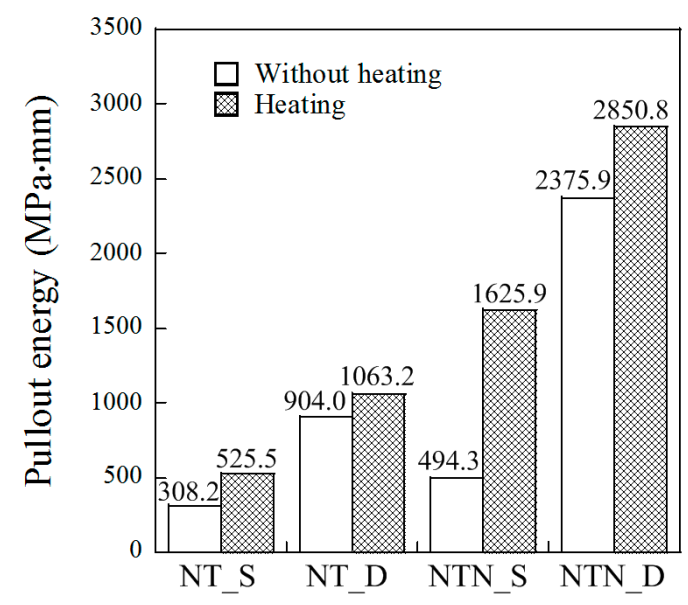

(a)

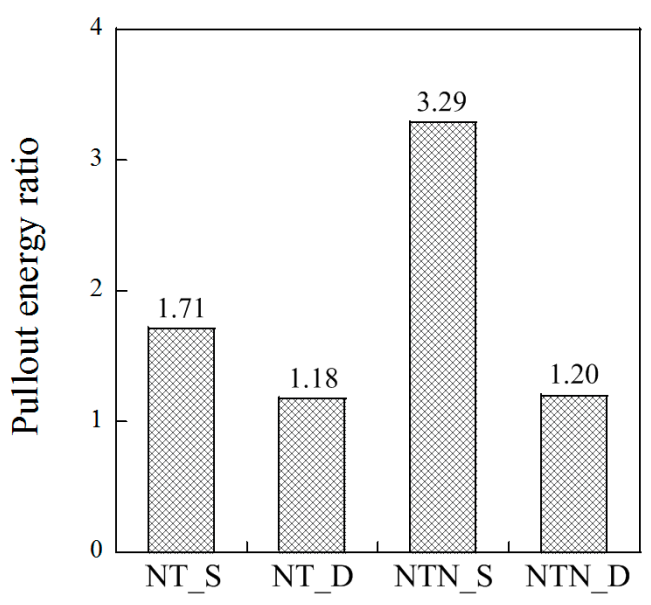

(b)

Figure 10. (a) Pullout energy (for samples with heating (grey) or without heating (white)), and (b) pullout energy ratio owing to the heating treatment.

\section{Conclusions}

This study investigated the effects of applying a short heat treatment period (10 $\mathrm{min}$ ) to shape memory alloy (SMA) fibers on their geometry and pullout resistance. The short heat treatment time clearly activated the shape memory effects, eventually generating the pullout stress recovery of SMA fibers in mortar. The conclusions below can be drawn from this experimental study:

- During the short heat treatment period, the length of the cold-drawn SMA fibers clearly decreased, whereas their diameter expanded due to the shape memory effect. The NiTi fibers generally showed greater shape memory effects in both diameter and length than the NiTiNb fibers, while the smooth geometry SMA fibers had greater shape memory effects than the dog-bone-shaped geometry fibers;

- SMA fibers with a dog-bone-shaped geometry generally showed higher pullout resistances than those with a smooth geometry;

- The short heat treatment period noticeably increased the pullout stress, although the degree of enhancement varied, relative to the SMA fiber alloy and geometry: (1) the NiTi fibers generally produced a faster pullout stress recovery than the NiTiNb fibers, while the SMA fibers with dog-bone-shaped geometries showed a faster recovery than those with a smooth geometry; (2) the NiTi fibers revealed higher pullout stress ratios during and after the heat treatment than the NiTiNb fibers; and (3) the SMA fibers with dog-bone-shaped geometries generated a larger amount of pullout energy $(P E)$, which is favorable for faster crack closing.

Self-healing concrete can close (heal or fill) cracks; however it requires a few days minimum to heal the cracks. Consequently, in this study, we found that the SMA-FRCCs have a fast crack closing capacity (just only $10 \mathrm{~min}$ ). The crack-closing behavior of SMA-FRCCs under a load is now under investigation and the parameters influencing the recovery start time require further investigation. Moreover, it is also necessary to investigate the residual stress of SMA-FRCCs [26].

Author Contributions: M.K.K., D.J.K., Y.-S.C., and E.C. conceived, designed, and wrote the manuscript; M.K.K. performed the experiments.

Funding: This research was supported by the Basic Science Research Program through the National Research Foundation of Korea (NRF) funded by the Ministry of Education, Science and Technology (Project No. 2019-R1A2C2008542).

Conflicts of Interest: The authors declare no conflicts of interest. 


\section{References}

1. Naaman, A.E.; Reinhardt, H.W. Characterization of high performance fiber reinforced cementitious composites-HPFRCC. In Proceedings of the Second International Workshop on High Performance Fiber Reinforced Cement Composites (HPFRCC2), Ann Arbor, MI, USA, 11-14 June 1995; pp. 1-24.

2. Orange, G.; Acker, P.; Vernet, C. A new generation of UHPConcrete: DUCTAL damage resistance and micro mechanical analysis. In Proceedings of the Third International Workshop on High Performance Fiber Reinforced Cement Composites (HPFRCC3), Mainz, Germany, 16-19 May 1999; pp. 101-112.

3. Rossi, P. High performance multimodal fiber reinforced cement composites (HPMFRCC): The LCPC experience. ACI Mater. J. 1997, 94, 478-483.

4. Rossi, P.; Arca, A.; Parant, E.; Fakhri, P. Bending and compressive behavior of a new cement composite. Cem. Concr. Res. 2005, 35, 27-33. [CrossRef]

5. Ahn, T.H.; Kishi, T. Crack self-healing behavior of cementitious composites incorporating various mineral admixtures. J. Adv. Concr. Technol. 2010, 8, 171-186. [CrossRef]

6. Li, M.; Li, V.C. Cracking and healing of engineered cementitious composites under chloride environment. ACI Mater. J. 2011, 108, 333-340.

7. Kim, D.J.; El-Tawil, S.; Naaman, A.E. Rate-dependent tensile behavior of high performance fiber reinforced cementitious composites. Mat. Struct. 2009, 42, 399-414. [CrossRef]

8. Blanco, A.; Pujadas, P.; Fuente, D.; Cavalaro, S.H.P.; Aguado, A. Influence of the type of fiber on the structural response and design of FRC slabs. J. Struct. Eng. 2016, 142, 04016054. [CrossRef]

9. Edvardsen, C. Water permeability and autogenous healing of cracks in concrete. ACI Mater. J. 1999, 96, 448-455.

10. Kim, D.J.; Kim, H.A.; Chung, Y.-S.; Choi, E. Pullout resistance of straight NiTi SMA fibers in cement mortar after cold drawing process and heat treatment. Compos. Part B Eng. 2014, 67, 588-594. [CrossRef]

11. Kim, D.J.; Kim, H.A.; Chung, Y.-S.; Choi, E. Pullout resistance of deformed shape memory alloy fibers embedded in cement mortar. J. Intell. Mat. Syst. Str. 2014, 27, 1-12. [CrossRef]

12. Kim, M.K.; Kim, D.J.; Chung, Y.-S.; Choi, E. Direct tensile behavior of shape-memory alloy fiber-reinforced cement composites. Constr. Build. Mater. 2016, 102, 462-470. [CrossRef]

13. Choi, E.; Nam, T.-H.; Cho, S.-C.; Chung, Y.-S.; Park, T. The behavior of concrete cylinders confined by shape memory alloy wires. Smart Mater. Struct. 2008, 17, 065032. [CrossRef]

14. Choi, E.; Chung, Y.-S.; Choi, J.-H.; Kim, H.-T.; Lee, H. The confining effectiveness of NiTiNb and NiTi SMA wire jackets for concrete. Smart Mater. Struct. 2010, 19, 035024. [CrossRef]

15. Choi, E.; Kim, Y.-W.; Chung, Y.-S.; Yang, K.-T. Bond strength of concrete confined by SMA wire jackets. Phys. Procedia 2010, 10, 210-215. [CrossRef]

16. Tran, H.; Balandraud, X.; Destrebecq, J.F. Improvement of the mechanical performances of concrete cylinders confined actively or passively by means of SMA wires. Arch. Civ. Mech. Eng. 2015, 15, 292-299. [CrossRef]

17. Sawaguchi, T.; Kikuchi, T.; Ogawa, K.; Kajiwara, S.; Ikeo, Y.; Kojima, M.; Ogawa, T. Development of prestressed concrete using Fe-Mn-Si-based shape memory alloys containing NbC. Mater. Trans. 2006, 41, 580-583. [CrossRef]

18. Umezaki, E. Improvement in separation of SMA from matrix in SMA embedded smart structures. Mat. Sci. Eng. A Struct. 2000, 285, 363-369. [CrossRef]

19. Lee, K.-J.; Lee, J.-H.; Jung, C.-Y.; Choi, E. Crack-closing performance of NiTi and NiTiNb fibers in cement mortar beams using shape memory effects. Compos. Struct. 2018, 202, 710-718. [CrossRef]

20. Lee, J.-H.; Lee, K.-J.; Choi, E. Flexural capacity and crack-closing performance of NiTi and NiTiNb shape-memory alloy fibers randomly distributed in mortar beams. Compos. Part B Eng. 2018, 153, 264-276. [CrossRef]

21. Wang, Y.; Zhou, L.; Wang, Z.; Huang, H.; Ye, L. Analysis of internal stresses induced by strain recovery in a single SMA fiber-matrix composite. Comp. Part B Eng. 2011, 42, 1135-1143. [CrossRef]

22. Watanabe, Y.; Miyazaki, E.; Okada, H. Enhanced mechanical properties of Fe-Mn-Si-Cr shape memory fiber/plaster smart composite. Mater. Trans. 2002, 43, 974-983. [CrossRef]

23. Kuang, Y.; Ou, J. Self-repairing performance of concrete beams strengthened using superelastic SMA wires in combination with adhesives released from hollow fiber. Smart Mater. Struct. 2008, 17, 025020. [CrossRef] 
24. Kodur, V.K.R.; Sultan, M.A. Effect of temperature on thermal properties of high strength concrete. J. Mater. Civil Eng. 2003, 15, 101-107. [CrossRef]

25. Kim, J.; Lee, G.-P.; Moon, D.Y. Evaluation of mechanical properties of steel-fibre-reinforced concrete exposed to high temperatures by double punch test. Constr. Build. Mater. 2015, 79, 182-191. [CrossRef]

26. Pujadas, P.; Blanco, A.; Cavalaro, S.H.P.; Fuente, A.; Aguado, A. Multidirectional double punch test to assess the post-cracking behaviour and fibre orientation of FRC. Constr. Build. Mater. 2014, 58, 214-224. [CrossRef]

(C) 2019 by the authors. Licensee MDPI, Basel, Switzerland. This article is an open access article distributed under the terms and conditions of the Creative Commons Attribution (CC BY) license (http://creativecommons.org/licenses/by/4.0/). 